\title{
INFLUENCIA DE LAS PACAS DE AVENA EN LA TEMPERATURA Y HUMEDAD EN LAS VIVIENDAS EN ZONAS ALTOANDINAS
}

Leonel Suasaca Pelinco, Alvaro Apaza Mamani, Jaime Augusto Flores Alfaro, Oscar Aaron Perca Chura y Wilson Quinto Machaca

\section{RESUMEN}

En la región Puno las viviendas de los pobladores de las zonas altoandinas carecen de aislante térmico, siendo afectadas por las bajas temperaturas, intensificándose el friaje de abril a julio. Esta investigación propone una vivienda típica de la zona Alto Andina, factible de construir en su totalidad con materiales propios de la zona en un tiempo mínimo y que genere un aislamiento térmico para lograr un confort térmico óptimo. En las zonas alto andinas del altiplano Peruano y Boliviano, la avena se produce a gran escala y es usado como forraje para la alimentación del ganado vacuno y ovino. Se ha empleado la avena seca comprimida conocida como "paca de avena" en los muros como material de construcción principal. Una vez construida la vivienda, se desarrolló la medición de los parámetros por un periodo de 21 días, periodo en el cual se registró la temperatura y la humedad dentro de la vivienda haciendo uso del higrómetro con cable para exterior e interior, obteniéndose las temperaturas mínimas, máximas y porcentaje de humedad en la vivienda construida con pacas de avena. Como resultado, se ha obtenido que la temperatura en la vivienda está entre $\operatorname{los} 9.7^{\circ} \mathrm{C}$ a $10.1^{\circ} \mathrm{C}$ y la humedad está entre $44 \%$ a $47 \%$, como valores máximos y mínimos respectivamente, a las cinco de la mañana, y $17.5^{\circ} \mathrm{C}$ a $18.3^{\circ} \mathrm{C}$ y $39 \%$ a $43 \%$ de humedad a las siete de la noche. Se obtuvieron diferencias con el exterior de $9^{\circ} \mathrm{C}$ como mínima y $9.8^{\circ} \mathrm{C}$ como temperatura máxima a las cinco de la mañana, $7.7^{\circ} \mathrm{C}$ como mínima y $8.9^{\circ} \mathrm{C}$ como máxima a las siete de la noche.

Palabras Claves: Confort Térmico, Bioclimáticas, Viviendas, Pacas de Avena.

DOI: 10.23881 /idupbo.020.1-15i 